\title{
Evaluasi Peningkatan Produksi Pada Formasi Sandstone Sumur \#H Dan \#P Dengan Perencanaan Stimulasi Pengasaman Matriks (Studi Kasus Lapangan Falih)
}

\author{
Ira Herawati ${ }^{1}$, Novrianti ${ }^{1}$, Arpan Suyandi ${ }^{1}$ \\ ${ }^{1}$ Program Studi Teknik Perminyakan Universitas Islam Riau
}

\begin{abstract}
Abstrak
Salah satu upaya stimulasi sumur yang dilakukan untuk meningkatkan produktivitas sumur yang mengalami penurunan produksi karena menurunnya permeabilitas akibat kerusakan formasi adalah dengan pengasaman matriks. Pengasaman matriks dapat dilakukan pada formasi sandstone menggunakan fluida stimulasi berbahan dasar asam Hydrofloric (HF) yang dicampur dengan asam Hydrochlorid $(\mathrm{HCl})$. Dalam pelaksanaannya perlu dilakukan perencanaan desain pengasaman matriks serta mengevaluasi hasil sebelum dan sesudah dilakukan stimulasi pengasaman matriks. Penggunaan Asam Hydrofloric pada batuan sandstone karena dapat melarutkan Silikat. Asam Hydrofloric bereaksi dengan Calsium (Ca) dan Mangan $(\mathrm{Mg})$ membentuk endapan. Pencampuran asam Hydrofloric dan Hydrochlorid akan dapat menghilangkan scale karena sementasi sandstone terdiri dari Ca dan Mg. Evaluasi keberhasilan stimulasi dilakukan pada sumur \#H dan \#P yang didasarkan pada laju produksi harian sumur, productivity index, kurva IPR (Inflow Performance Relationship) Wiggins serta harga permeabilitas sumur. Dari hasil penelitian yang dilakukan pada sumur \#H mengalami peningkatan produksi dari 81.125 BOPD menjadi 121.365 BOPD dengan kenaikan harga productivity index dari $0.12 \mathrm{bbl} / \mathrm{day} / \mathrm{psi} \mathrm{menjadi} 0.2$ bbl/day/psi dan kenaikan harga permeabilitas dari $11.65 \mathrm{mDarcy}$ menjadi $17.79 \mathrm{mDarcy}$. Hasil pengamatan yang dilakukan pada sumur \#P mengalami penurunan produksi dari 40.89 BOPD menjadi 34.94 BOPD dengan penurunan harga productivity index dari $0.10 \mathrm{bbl} / \mathrm{day} / \mathrm{psi}$ menjadi $0.09 \mathrm{bbl} /$ day/psi dan penurunan harga permeabilitas dari $10.76 \mathrm{mDarcy}$ menjadi 9.42 mDarcy.
\end{abstract}

Kata Kunci: Stimulasi, Sandstone, Scale, Inflow Performance Relationship

Alamat email korespondensi penulis: iraherawati@eng.uir.ac.id

\section{PENDAHULUAN}

Pada dasarnya stimulasi sumur minyak memiliki peranan yang sangat penting dalam kegiatan produksi. Salah satu jenis metode stimulasi adalah dengan menginjeksikan asam kedalam pori-pori dan matriks batuan pada suatu tekanan dasar sumur yang lebih kecil dari tekanan rekah formasinya, dengan tujuan agar reaksi pengasaman menyebar ke dalam formasi secara radial (Guin, J.A. \& Schechter, R.S., 1971). Ada beberapa jenis formasi batuan di reservoir, salah satunya yang akan diteliti adalah formasi batu pasir (sandstone). Formasi batuan pasir (sandstone) pada umumnya terdiri dari kuarsa, biji-bijian silikat, feldspars, rijang dan mika. Mineral ini terikat bersama oleh mineral sekunder yang diendapkan dari air bawaan (connate water), menempati sebagian ruang berpori pada batuan karbonat dan lempung pori-pori. Fraksi berpori dan permeabilitas batuan pembentuk akan dilewati invasi dasar air filtrat, baik dari pengeboran, komplesi, workover atau treatment fluida (Williams et al, 1979).

Invasi ini dapat merusak matriks dengan pengembangan dan pendispersi lempung atau bahkan dengan menginduksi pengendapan scale. Beberapa partikel juga bisa menyebabkan pembentukan permeabilitas yang tinggi di bawah tekanan diferensial dan formasi berpori, Campuran asam chlorida-fluorida ( $\mathrm{HCl}-$ $\mathrm{HF}$ ) umumnya digambarkan sebagai asam lumpur, biasanya digunakan untuk treatment formasi batu 
pasir yang mana campuran ini melarutkan clay dari lumpur pengeboran dan bereaksi dengan sebagian besar konstituen dari pembentukan batu pasir (Ayorinde, A., Granger, C. and Thomas, R.L, 1992)

Penelitian ini dilakukan pada sumur \#H dan \#P terletak pada formasi Falih yang merupakan formasi batuan sandstone. Sumur \#H dan \#P terindikasi mengalami penurunan laju produksi, terlihat dari penurunan jumlah produksi minyak. Berdasarkan hasil pengujian sebelumnya, sumur \#H memiliki nilai skin sebesar $8.17(\mathrm{~S}=+)$ dan sumur \#P memiliki nilai skin sebesar $5.21(\mathrm{~S}=+)$. Berdasarkan well history, kedua sumur ini pernah dilakukan stimulasi pengasaman.

Penelitian ini bertujuan membuat desain pengasaman matriks yang cocok untuk sumur \#H dan \#P serta mengevaluasi hasil produksi sebelum dan sesudah dilakukan pengasaman matriks berdasarkan laju produksi harian, productivity index, kurva IPR dan permeabilitas.

\section{METODE PENELITIAN}

Metode yang dilakukan pada penelitian ini meliputi kegiatan terstruktur mulai dari melakukan studi literatur, mempersiapkan data, dan melakukan pengolahan data sesuai dengan prosedur yang terdapat pada beberapa literatur yang ada. Dalam penelitian dilakukan pengumpulkan data-data lapangan, data reservoir, data produksi, dan data komplesi dari sumur \#H dan \#P. Berdasarkan Investigasi data-data dan well history dilakukan analisa penurunan kurva produksi dari suatu sumur minyak yang mengalami decline produksi akibat damage yang terjadi.

Pemilihan kandidat sumur yang akan distimulasi pengasaman dengan indikator terjadinya penurunan produksi pada sumur kandidat tersebut. Setelah itu dilakukan pengujian sample air formasi yang dilakukan dilaboratorium untuk menegtahui masalah yang terjadi pada sumur kandidat tersebut. Menerapkan stimulasi pengasaman matriks untuk mengatasi scale yang terdapat pada sumur kandidat dan selanjutnya dilakukan evaluasi sebelum dan setelah dilakukan desain pengasaman. Hasil evaluasi ini akan membawa kepada kesimpulan yang merupakan tujuan dari penelitian.

\section{Initial Data Reservoir}

Pemboran Pertama kali pada sumur \#H dilakukan pada tahun 1949 dengan kedalaman 4,489.8 ft. Sumur \#H memproduksikan minyak dan gas yang berasal dari formasi C,A,D dan E lapangan Falih. Interval Perforasi zona C (2,692.06 ft-2,785.56 ft), Zona A (3,753.46 ft-3,809.24 ft), Zona D (3,203.89 $\mathrm{ft}-3,248.19 \mathrm{ft}), \mathrm{E}(2,893.84 \mathrm{ft}-3015.23 \mathrm{ft})$. Sumur \#H diproduksikan hanya dari dua zona yang masih produktif yaitu zona $\mathrm{D}$ dan A dengan komplesi commingle.

Sumur\# H sudah beberapa kali di lakukan stimulasi. Berdasarkan history sumur \#H, pada bulan Januari 2003 telah dilakukan stimulasi acid washing. Pada bulan Februari 2005 kembali dilakukan stimulasi acid washing. Selang empat bulan berikutnya, tepatnya bulan Juni 2005 dilakukan program WSR (Wax Scale Removal). Memasuki bulan januari 2009 produksi mengalami penurunan. Pengasaman pada sumur \#H akan dilakukan pada lapisan D dan A.

Pemboran pertama kali pada sumur \#P dilakukan pada tahun 2005 dengan kedalaman 3,865.02 ft. Sumur \#P memproduksikan minyak dan gas yang berasal dari formasi E,D,B dan A lapangan Falih. Sumur \#P memiliki 4 zona perforasi yaitu zona E $(2,713.28 \mathrm{ft}-2,719.94 \mathrm{ft})$ dan $(2,733.07 \mathrm{ft}-2,737.99 \mathrm{ft})$, zona D (3,041.48 ft-3,054.61 ft) dan $(3,071.01 \mathrm{ft}-3,077.57 \mathrm{ft})$, zona B $(3.379 .43 \mathrm{ft}-3,399.11 \mathrm{ft})$, 
$(3,431.92 \mathrm{ft}-3,451.61 \mathrm{ft}),(3,461 \mathrm{ft}-3,484.42 \mathrm{ft})$ dan zona A $(3,559.88 \mathrm{ft}-3,569.72 \mathrm{ft}),(3,586.13 \mathrm{ft}-$ $3,605.81 \mathrm{ft}),(3,614.02 \mathrm{ft}-3,623.86 \mathrm{ft}),(3.630 .42 \mathrm{ft}-3,640.26 \mathrm{ft}),(3,646.83 \mathrm{ft}-3,659.95 \mathrm{ft}),(3,691.12 \mathrm{ft}-$ 3,710.81 ft). Sumur \#P diproduksikan hanya dari satu zona yang masih produktif yaitu zona A. pada bulan Februari 2007 dilakukan stimulasi acid washing pada sumur \#P. Pengerjaan stimulasi pengasaman matriks akan di lakukan pada zona A sumur \#P.

Kerusakan formasi yang terjadi pada sumur \#H dan \#P diidentifikasi dari hasil pengamatan laju produksi. Kedua sumur ini mengalami penurunan laju produksi yang cukup signifikan. Untuk itu dilakukan proses pengasaman matriks terhadap kedua sumur ini. Evaluasi yang akan dilakukan adalah dengan melihat perubahan laju produksi sebelum pengasaman matriks dan setelah pengasaman matriks, sehingga proses stimulasi yang dilakukan akan memberikan gambaran sejauh mana stimulasi ini berhasil dilakukan.

Untuk membuat desain pengasaman matriks pada sumur yang akan distimulasi, ada beberapa data karakteristik dari reservoir dan produksi yang diperlukan yakni meliputi penentuan gradien rekah $\left(\mathrm{G}_{\mathrm{f}}\right)$, tekanan rekah formasi (BHP rekah), tekanan maksimum di permukaan $\left(\mathrm{P}_{\max }\right)$, perkiraan harga injeksi maksimal agar tidak terjadi perekahan $(i$ max $)$ dan volume asam (V) (Guin, J.A. and Schechter, R.S, 1971). Masing-masing data yang dibutuhkan untuk sumur $H$ seperti dapat dilihat pada tabel 1, tabel 2, tabel 3, dan tabel 4 .

Tabel 1 Data Casing Sumur \#H

\section{Data Casing}

\begin{tabular}{ccclc}
\hline Weight & OD & ID & Volume Faktor & Depth \\
\hline $20 \mathrm{lbs} / \mathrm{ft}$ & 6.625 inch & 6.049 inch & 0.0355 inch & $4,029.07 \mathrm{ft}$ \\
\hline
\end{tabular}

Tabel 2 Data Tubing Sumur \#H

Data Tubing

\begin{tabular}{ccccc}
\hline Weight & OD & ID & Volume Faktor & Depth \\
\hline $6.5 \mathrm{lbs} / \mathrm{ft}$ & 2.875 inch & 2.441 inch & 0.0058 inch & $3,187.49 \mathrm{ft}$ \\
\hline
\end{tabular}

Tabel 3 Data Interval Perforasi Sumur \#H

Interval Perforasi

\begin{tabular}{ll}
\hline Zona D & $3,203.9 \mathrm{ft}-3,248.19 \mathrm{ft}$ \\
\hline Net & $44.3 \mathrm{ft}$ \\
\hline Zona A & $3,753.64 \mathrm{ft}-3809.24 \mathrm{ft}$ \\
\hline Net & $55.7 \mathrm{ft}$ \\
\hline
\end{tabular}


Tabel 4 Data Sebelum Pengasaman Sumur \#H

Data

\begin{tabular}{lcc}
\hline \multicolumn{1}{c}{ Parameter } & Zona D & Zona A \\
\hline SFL & $1,715.96$ & $1,679.87$ \\
\hline WFL & 2,779 & $3,156.32$ \\
\hline Datum & 3,226 & $3,781.53$ \\
\hline SG Oil & 0.8313 & 0.8313 \\
\hline SG water & 1 & 1 \\
\hline Water Cut & 87.5 & 87.5 \\
\hline Viscositas Minyak & 5.72 & 5.72 \\
\hline
\end{tabular}

Berdasarkan perhitungan Pr dan PWF yang dilakukan di zona D dan zona $\mathrm{H}$ maka didapatkan harga rata-rata Pr dan PWF reservoir sebelum dilakukan pengasaman sumur seperti terlihat pada tabel 5.

Tabel 5 Data Pr dan PWF Rata-rata Sebelum Pengasaman Sumur \#H

\section{Data}

\begin{tabular}{lc}
\hline Parameter & Nilai \\
\hline Pr & 765.41 Psi \\
\hline Pwf & 140.67 Psi \\
\hline
\end{tabular}

Tabel 6, tabel 7, tabel 8, dan tabel 9 menunjukkan masing-masing data yang dibutuhkan untuk perencanaan pengasaman matriks pada sumur \#P.

Tabel 6 Data Casing Sumur \#P

Data Casing

\begin{tabular}{ccccc}
\hline Weight & OD & ID & Volume Faktor & Depth \\
\hline $23 \mathrm{lbs} / \mathrm{ft}$ & 6.625 inch & 6.049 inch & 0.0355 inch & $3,855.18 \mathrm{ft}$ \\
\hline
\end{tabular}

Tabel 7 Data Tubing Sumur \#P

Data Tubing

\begin{tabular}{ccccc}
\hline Weight & OD & ID & Volume Faktor & Depth \\
\hline 6.5 lbs/ft & 3.5 inch & 2.992 inch & 0.0087 inch & $3,793.98 \mathrm{ft}$ \\
\hline
\end{tabular}


Tabel 8 Data Interval Perforasi Sumur \#P

Interval Perforasi

\begin{tabular}{ll}
\hline Zona A & $3,559.89 \mathrm{ft}-3,710.81 \mathrm{ft}$ \\
\hline Net & $83.67 \mathrm{ft}$ \\
\hline
\end{tabular}

Tabel 9 Data Sebelum Pengasaman Sumur \#P

Data

\begin{tabular}{ll}
\multicolumn{1}{c}{ Parameter } & \multicolumn{1}{c}{ Zona A } \\
\hline SFL & $1,991.56$ \\
\hline WFL & $2,959.462$ \\
\hline Datum & $3,635.34$ \\
\hline SG Oil & 0.8313 \\
\hline Water Cut & $53 \%$ \\
\hline Viscositas Minyak & 6.5
\end{tabular}

\section{HASIL DAN PEMBAHASAN}

Berdasarkan data-data sumur dan reservoir untuk sumur \#H maka dilakukan perencanaan desain masing-masing sumur \#H dan sumur \#P.

\section{Desain Pengasaman Matriks Sumur \#H Zona D dan zona A}

Dengan diketahuinya harga tekanan rekah formasi, maka dapat diatur berapa besar tekanan yang diperlukan untuk menginjeksikan asam agar tidak terjadi rekahan pada formasi. Besarnya harga tekanan rekah formasi dapat ditentukan berdasarkan harga gradien tekanan rekah (Williams et al, 1979).

Dari hasil perhitungan didapatkan harga gradient rekah untuk Zona D sebesar 2.291,8 Psia dan untuk zona A sebesar 2.684,5 Psia. Selanjutnya ditentukan tekanan injeksi maksimal permukan untuk dapat diinjeksikan dibawah tekanan rekah dan dari hasil perhitungan didapatkan tekanan maksimal zona $\mathrm{D}$ sebesar 768,08 Psia dan untuk zona A sebesar 899,69 Psia. Dari perhitungan yang dilakukan untuk injeksi maksimal agar tidak terjadi perekahan diperoleh nilai injeksi maksimal pada zona D adalah sebesar $0,85 \mathrm{bbl} / \mathrm{min}$ sedangkan untuk zona A injeksi maksimal sebesar 0,63 bbl/min.

Untuk mengetahui seberapa banyak volume asam yang akan diinjeksikan, maka harus ditentukan volume casing zona. Dari perhitungan yang dilakukan didapatkan volume asam injeksi di zona D sebanyak 687 galon sedangkan untuk zona A sebanyak 864 galon. Selanjutnya ditentukan volume over flush untuk masing-masing zona D dan A dan dari perhitungan didapatkan volume over flush untuk zona D adalah sebesar 846 galon sedangkan pada zona A adalah sebesar 997 galon. 


\section{Desain Pengasaman Matriks Sumur \#P}

Dari hasil perhitungan didapatkan harga gradient rekah untuk sumur \#P yang berada di zona A sebesar 2.412 Psia. Selanjutnya ditentukan tekanan injeksi maksimal permukan untuk dapat diinjeksikan dibawah tekanan rekah dan dari hasil perhitungan didapatkan tekanan maksimal 685 Psia. Dari perhitungan yang dilakukan untuk injeksi maksimal agar tidak terjadi perekahan diperoleh nilai injeksi maksimal pada sumur \#P adalah sebesar $0.39 \mathrm{bbl} / \mathrm{min}$.

Dari perhitungan yang dilakukan didapatkan volume asam injeksi di zona A sumur \#P sebanyak 5.981galon. Selanjutnya ditentukan volume over flush dan dari perhitungan didapatkan volume over flush untuk zona A sumur \#P sebesar adalah sebesar 1.510,7 galon.

\section{Evaluasi Keberhasilan Stimulasi Pengasaman Matriks}

Setelah melakukan serangkaian proses stimulasi pengasaman matriks pada sumur \#H dan \#P perlu dilakukan suatu evaluasi terhadap hasil yang dilakukan pada sumur tersebut agar kita mengetahui seberapa besar tingkat keberhasilan tehadap pekerjaan stimulasi yang telah kita lakukan. Dalam hal ini hasil evaluasi yang dilakukan didasarkan terhadap hasil yang diperoleh sebelum pengasaman dan setelah pengasaman. Evaluasi yang dilakukan di dadasarkan pada laju produksi sumur. productivity index. kurva IPR dan Permeabilitas.

Tabel 10 Data Sesudah Pengasaman Sumur \#P

\begin{tabular}{ll}
\multicolumn{2}{c}{ Data } \\
\multicolumn{1}{c}{ Parameter } & \multicolumn{1}{c}{ Nilai } \\
\hline Pr & $765.41 \mathrm{Psi}$ \\
\hline Pwf & $153.63 \mathrm{Psi}$ \\
\hline SFL & $1,692.99 \mathrm{ft}$ \\
\hline WFL & $3,146.48 \mathrm{ft}$ \\
\hline Datum & $3,506.56 \mathrm{ft}$ \\
\hline SG Oil & 0.8313 \\
\hline SG water & 1 \\
\hline Water Cut & $91.3 \%$ \\
\hline Viscositas Minyak & 5.72 \\
\hline GF & 0.426645 \\
\hline
\end{tabular}

\section{Evaluasi Sumur \#H Sesudah Pengasaman Matriks}

Menggunakan data-data sumur \#H sebelum pengasaman matriks dilakukan maka ditentukan parameterparameter sumur dan reservoir setelah pengasaman matrik. Dari perhitungan yang dilakukukan didapatkan tekanan dasar sumur (Pwf) sesudah melakukan pengasaman sebesar 153,63 Psia dan laju alir minyak (Qoil) sesudah pengasaman sebesar 121,365 BOPD. Dari perhitungan tersebut didapatkan data sumur \#H setelah pengasaman matriks dilakukan seperti terlihat pada tabel 10.

Perbadingan data sumur sebelum dan sesudah pengasaman matriks dilakukan dapat dilihat pada tabel 11. 
Tabel 11 Data sumur \#H sebelum dan sesudah pengasaman Matriks

\begin{tabular}{lll}
\hline \multirow{2}{*}{ Parameter } & \multicolumn{2}{c}{ Data } \\
\cline { 2 - 3 } \multicolumn{1}{c}{ Sebelum } & \multicolumn{1}{c}{ Sesudah } \\
\hline Pr & 765.41 Psi & $765.41 \mathrm{Psi}$ \\
\hline Pwf & $140.67 \mathrm{Psi}$ & $153.63 \mathrm{Psi}$ \\
\hline SFL & $1.715 .96 \mathrm{ft}$ & $1,692.99 \mathrm{ft}$ \\
\hline WFL & $3,225.22 \mathrm{ft}$ & $3,146.48 \mathrm{ft}$ \\
\hline Datum & $3,506.56 \mathrm{ft}$ & $3,506.56 \mathrm{ft}$ \\
\hline SG Oil & 0.8313 & 0.8313 \\
\hline SG water & 1 & 1 \\
\hline Water Cut & $87.5 \%$ & $91.3 \%$ \\
\hline Viscositas Minyak & 5.72 & 5.72 \\
\hline GF & 0.426645 & 0.426645 \\
\hline
\end{tabular}

\section{Evaluasi Sumur \#P Sesudah Pengasaman Matriks}

Hal yang sama seperti pada sumur \#H juga dilakukan pada sumur \#P. Menggunakan data sumur sebelum pengasaman matriks dilakukan ditentukan data sumur setelah pengasaman. Dari perhitungan yang dilakukan didapatkan Pwf setelah pengasaman sebesar 273,5 Psia dan Qoil sebesar 34,944 BOPD. Dari perhitungan yang didapatkan data sesudah pengasaman seperti terlihat pada tabel 12 .

Tabel 12 Data Sesudah Pengasaman Sumur \#P

\begin{tabular}{ll}
\hline \multicolumn{2}{c}{ Data } \\
\hline \multicolumn{1}{c}{ Parameter } & \multicolumn{1}{c}{ Nilai } \\
\hline Pr & 655.32 Psi \\
\hline Pwf & $281.43 \mathrm{Psi}$ \\
\hline SFL & $1,952.19 \mathrm{ft}$ \\
\hline WFL & $2,946.33 \mathrm{ft}$ \\
\hline Datum & $3,635.48 \mathrm{ft}$ \\
\hline SG Oil & 0.8313 \\
\hline SG water & 1 \\
\hline Water Cut & $66.4 \%$ \\
\hline Viscositas Minyak & 6.5 \\
\hline GF & 0.426645 \\
\hline
\end{tabular}

Perbadingan data sumur sebelum dan sesudah pengasaman matriks dilakukan pada sumur \#P dapat dilihat pada tabel 13 .

\section{Penentuan Keberhasilan Pengasaman Matriks Sumur \#H}

Keberhasilan stimulasi pengasaman matriks pada sumur \#H zona A dan zona D dapat dievaluasi berdasarkan dari kenaikan laju produksi dan hasil grafik kurva Inflow Performance Relationship (IPR) sebelum dan sesudah pengasaman dengan menggunakan metode Wiggins dan peningkatan harga Productivity Index $(\mathrm{PI})$. 
Tabel 13 Data Sebelum dan Sesudah Pengasaman Sumur \#P

\begin{tabular}{lll}
\hline \multirow{2}{*}{ Parameter } & \multicolumn{2}{c}{ Data } \\
\cline { 2 - 3 } \multicolumn{1}{c}{ Sebelum } & \multicolumn{1}{c}{ Sesudah } \\
\hline Pr & 655.32 Psi & $655.32 \mathrm{Psi}$ \\
\hline Pwf & $269.45 \mathrm{Psi}$ & $273.65 \mathrm{Psi}$ \\
\hline SFL & $1,991.56 \mathrm{ft}$ & $1,952.19 \mathrm{ft}$ \\
\hline WFL & $2,959.46 \mathrm{ft}$ & $2,946.33 \mathrm{ft}$ \\
\hline Datum & $3,635.34 \mathrm{ft}$ & $3,635.34 \mathrm{ft}$ \\
\hline SG Oil & 0.8313 & 0.8313 \\
\hline SG water & 1 & 1 \\
\hline Water Cut & $53 \%$ & $66.4 \%$ \\
\hline Viscositas Minyak & 6.5 & 6.5 \\
\hline GF & 0.426645 & 0.426645 \\
\hline
\end{tabular}

\section{Perhitungan Berdasarkan Laju Produksi}

Dalam melakukan evaluasi berdasarkan Laju Produksi. perhitungan yang dilakukan menggunakan data Pr dan Pwf test yang telah didapat dari hasil test sonolog. Harga qo dan qw dihitung berdasrakan hasil q test yang diperoleh dari hasil swab test yang dilakukan. Selanjutnya harga qo max dan qw max sebelum dan sesudah proses pengasaman dihitung dengan menggunakan persamaan metode Wiggins (Wiggins, 1994).

Menggunakan persamaan didapatkan harga Qo maksimal 91,32 BOPD dan Qw maksimal sebelum pengasaman pada Pwf test 140,67 Psia sebesar dan 662,13 BWPD. Sedangkan untuk setelah dilakukan pengasaman pada Pwf test 153,63 psia didapatkan Qo maksimal sebesar 138,47 BOPD dan Qw maksimal 1.509,83 BWPD.

Perhitungan Berdasarkan Productivity Index

Productivity Index (PI) yang diperoleh sebelum pengasaman adalah

$$
\begin{aligned}
P I & =\frac{Q}{p_{r}-P_{w f}} \\
& =\frac{81.125}{765.41-140,67} \\
& =0.12 \mathrm{Stbbls} / \mathrm{D} / \mathrm{Psi}
\end{aligned}
$$

Productivity Index (PI) yang diperoleh sesudah pengasaman matriks adalah

$$
\begin{aligned}
P I & =\frac{Q}{P r-P w f} \\
& =\frac{121.365}{765.41-153.63} \\
& =0.2 \mathrm{Stbbls} / \mathrm{D} / \mathrm{Psi}
\end{aligned}
$$

\section{Perhitungan Berdasarkan IPR Wiggins}

Kurva inflow performance relationship (IPR) adalah plot antara tekanan alir dasar sumur $\left(\mathrm{P}_{\mathrm{wf}}\right)$ versus laju produksi (Q). Metode yang digunakan untuk analisa sumur \#H ini adalah metode Wiggins. 
Menggunakan persamaan pada kondisi sebelum pengasaman untuk Pwf test 77 Psia dan Pe 765,41 Psia diperoleh Qo 86,14 BOPD dan Qw sebesar 612, 43 BWPD. Sehinggs didapatkan total fluida 698, 57 BFPD dengan water cut $87,66 \%$. Perhitungan laju alir sumur sumur $\mathrm{H}$ sebelum pengasaman untuk berbagai PWF asumsi seperti terlihat pada tabel 14, dan perhitungan sesudah pengasaman matrik seperti terlihat pada tabel 15 .

Tabel 14 Laju Alir Sumur \#H Sebelum Pengasaman Dari Beberapa Harga Pwf Asumsi

\begin{tabular}{lllll}
\hline $\begin{array}{c}\text { Pwf } \\
(\text { Psi) }\end{array}$ & $\begin{array}{c}\text { Oil } \\
\text { (BOPD) }\end{array}$ & $\begin{array}{c}\text { Water } \\
\text { (BWPD) }\end{array}$ & $\begin{array}{c}\text { Fluida } \\
\text { (BFPD) }\end{array}$ & $\begin{array}{c}\text { Water Cut } \\
(\%)\end{array}$ \\
\hline 0 & 91.32 & 662.13 & 753.46 & 87.87951 \\
\hline 38 & 88.84 & 637.75 & 726.59 & 87.77278 \\
\hline 77 & 86.14 & 612.43 & 698.57 & 87.66877 \\
\hline 115 & 83.22 & 586.16 & 669.38 & 87.56727 \\
\hline 153 & 80.08 & 558.95 & 639.03 & 87.46807 \\
\hline 191 & 76.72 & 530.79 & 607.52 & 87.37095 \\
\hline 230 & 73.15 & 501.70 & 574.84 & 87.27567 \\
\hline 268 & 69.35 & 471.66 & 541.01 & 87.18193 \\
\hline 306 & 65.33 & 440.68 & 506.01 & 87.0894 \\
\hline 344 & 61.09 & 408.75 & 469.84 & 86.99767 \\
\hline 383 & 56.63 & 375.89 & 432.52 & 86.9062 \\
\hline 421 & 51.96 & 342.08 & 394.03 & 86.81425 \\
\hline 459 & 47.06 & 307.32 & 354.38 & 86.72076 \\
\hline 498 & 41.94 & 271.63 & 313.57 & 86.62411 \\
\hline 536 & 36.61 & 234.99 & 271.59 & 86.52163 \\
\hline 574 & 31.05 & 197.41 & 228.46 & 86.40854 \\
\hline 612 & 25.28 & 158.88 & 184.16 & 86.27524 \\
\hline 651 & 19.28 & 119.42 & 138.70 & 86.09903 \\
\hline 689 & 13.07 & 79.01 & 92.07 & 85.80966 \\
\hline 727 & 6.63 & 37.65 & 44.28 & 85.02691 \\
\hline 765 & 0.00 & 0.00 & 0.00 & 0.0 \\
\hline
\end{tabular}

\section{Perhitungan Berdasarkan Permeabilitas}

Berdasarkan data-data yang ada maka dilakukan perhitungan harga permeabilitas $(\mathrm{K})$ pada reservoir dan dari perhitungan didapatkan harga permeabilitas sebelum pengasaman adalah sebesar 11,65 $\mathrm{mD}$ dan setelah pengasaman sebesar 17,79 $\mathrm{mD}$.

\section{Perhitungan Pengasaman Matriks Sumur \#P}

Keberhasilan stimulasi pengasaman matriks pada sumur \#P zona A dapat dievaluasi berdasarkan dari kenaikan laju produksi dan hasil grafik kurva Inflow Performance Relationship (IPR) sebelum dan sesudah pengasaman dengan menggunakan metode wiggins dan peningkatan harga Productivity Index (PI). 
Tabel 15 Laju Alir Sumur \#H Sesudah Pengasaman Dari Beberapa Harga Pwf Asumsi

\begin{tabular}{lllll}
\hline $\begin{array}{c}\text { Pwf } \\
\text { (Psi) }\end{array}$ & $\begin{array}{c}\text { Oil } \\
\text { (BOPD) }\end{array}$ & $\begin{array}{c}\text { Water } \\
(\text { BWPD) }\end{array}$ & $\begin{array}{c}\text { Fluida } \\
\text { (BFPD) }\end{array}$ & $\begin{array}{c}\text { Water Cut } \\
(\%)\end{array}$ \\
\hline 0 & 138.48 & 1509.83 & 1648.31 & 91.5987 \\
\hline 38 & 134.72 & 1454.23 & 1588.95 & 91.52156 \\
\hline 77 & 130.62 & 1396.48 & 1527.11 & 91.44633 \\
\hline 115 & 126.20 & 1336.59 & 1462.78 & 91.37287 \\
\hline 153 & 121.44 & 1274.54 & 1395.97 & 91.30102 \\
\hline 191 & 116.34 & 1210.34 & 1326.68 & 91.23062 \\
\hline 230 & 110.92 & 1144.00 & 1254.91 & 91.16151 \\
\hline 268 & 105.16 & 1075.50 & 1180.65 & 91.09348 \\
\hline 306 & 99.06 & 1004.85 & 1103.91 & 91.02628 \\
\hline 344 & 92.64 & 932.06 & 1024.69 & 90.95962 \\
\hline 383 & 85.88 & 857.11 & 942.99 & 90.8931 \\
\hline 421 & 78.78 & 780.02 & 858.80 & 90.8262 \\
\hline 459 & 71.36 & 700.77 & 772.13 & 90.75812 \\
\hline 498 & 63.60 & 619.37 & 682.98 & 90.6877 \\
\hline 536 & 55.51 & 535.83 & 591.34 & 90.61298 \\
\hline 574 & 47.08 & 450.13 & 497.22 & 90.53046 \\
\hline 612 & 38.33 & 362.29 & 400.62 & 90.43312 \\
\hline 651 & 29.24 & 272.30 & 301.53 & 90.30429 \\
\hline 689 & 19.81 & 180.15 & 199.96 & 90.09238 \\
\hline 727 & 10.05 & 85.86 & 95.91 & 89.51701 \\
\hline 765 & 0.00 & 0.00 & 0.00 & 0.0 \\
\hline
\end{tabular}

\section{Perhitungan Berdasarkan Laju Produksi}

Pada sumur \#P menggunakan persamaan didapatkan harga Qo maksimal 57,98 BOPD dan Qw maksimal sebelum pengasaman pada Pwf test 269,45 Psia sebesar dan 70,40 BWPD. Sedangkan untuk setelah dilakukan pengasaman pada Pwf test 278,75 psia didapatkan Qo maksimal sebesar 50,48 BOPD dan Qw maksimal 107,48 BWPD.

\section{Perhitungan Berdasarkan Productivity Index}

Productivity Index (PI) yang diperoleh sebelum pengasaman matriks adalah

$$
\begin{aligned}
P I & =\frac{Q}{p_{r}-P_{w f}} \\
& =\frac{40.89}{655.32-269.45} \\
& =0.10 \mathrm{Stbbls} / \mathrm{D} / \mathrm{Psi}
\end{aligned}
$$

Productivity Index (PI) yang diperoleh setelah pengasaman matriks adalah

$$
\begin{aligned}
P I & =\frac{Q}{P r-P w f} \\
& =\frac{34.94}{655.32-278.75}
\end{aligned}
$$




$$
=0.09 \mathrm{Stbbls} / \mathrm{D} / \mathrm{Psi}
$$

Tabel 16 Laju Alir Sumur \#P Sebelum Pengasaman Dari Beberapa Harga Pwf Asumsi

\begin{tabular}{lllll}
\hline $\begin{array}{c}\text { Pwf } \\
\text { (Psi) }\end{array}$ & $\begin{array}{c}\text { Oil } \\
\text { (BOPD) }\end{array}$ & $\begin{array}{c}\text { Water } \\
\text { (BWPD) }\end{array}$ & $\begin{array}{c}\text { Fluida } \\
\text { (BFPD) }\end{array}$ & $\begin{array}{c}\text { Water Cut } \\
(\%)\end{array}$ \\
\hline 0 & 57.98 & 70.41 & 128.39 & 54.838661 \\
\hline 33 & 56.41 & 67.82 & 124.23 & 54.59133 \\
\hline 66 & 54.69 & 65.12 & 119.82 & 54.351852 \\
\hline 98 & 52.84 & 62.33 & 115.17 & 54.119634 \\
\hline 131 & 50.85 & 59.44 & 110.28 & 53.89408 \\
\hline 164 & 48.71 & 56.44 & 105.16 & 53.674575 \\
\hline 197 & 46.44 & 53.35 & 99.79 & 53.460471 \\
\hline 229 & 44.03 & 50.15 & 94.19 & 53.251054 \\
\hline 262 & 41.48 & 46.86 & 88.34 & 53.045513 \\
\hline 295 & 38.79 & 43.47 & 82.25 & 52.842878 \\
\hline 328 & 35.96 & 39.97 & 75.93 & 52.641926 \\
\hline 360 & 32.99 & 36.38 & 69.36 & 52.441036 \\
\hline 393 & 29.88 & 32.68 & 62.56 & 52.237917 \\
\hline 426 & 26.63 & 28.88 & 55.51 & 52.029117 \\
\hline 459 & 23.24 & 24.99 & 48.23 & 51.809036 \\
\hline 491 & 19.72 & 20.99 & 40.71 & 51.567726 \\
\hline 524 & 16.05 & 16.90 & 32.94 & 51.285377 \\
\hline 557 & 12.24 & 12.70 & 24.94 & 50.915519 \\
\hline 590 & 8.30 & 8.40 & 16.70 & 50.31638 \\
\hline 623 & 4.21 & 4.00 & 8.21 & 48.745212 \\
\hline 655 & 0.00 & 0.00 & 0.00 & 0.00 \\
\hline & & & &
\end{tabular}

\section{Perhitungan Berdasarkan IPR Wiggins}

Kurva inflow performance relationship (IPR) adalah plot antara tekanan alir dasar sumur ( $\left.\mathrm{P}_{\mathrm{wf}}\right)$ versus laju produksi (Q). Metode yang digunakan untuk analisa sumur \#Pini adalah metode Wiggins. Dari gambar perbandingan kurva IPR dapat dilihat bahwa terjadi perbedaan harga laju alir (Q) sebelum dan setelah pengasaman pada tekanan drawdown tertentu, dimana $\mathrm{Q}$ setelah pengasaman lebih besar daripada sebelum pengasaman.

Menggunakan persamaan pada kondisi sebelum pengasaman untuk Pwf test 98 Psia dan Pr 651,72 Psia diperoleh Qo 52,84 BOPD dan Qw sebesar 62, 33 BWPD. Sehingga didapatkan total fluida 115, 17 BFPD dengan water cut 54,11\%. Perhitungan laju alir sumur sumur $\mathrm{H}$ sebelum pengasaman untuk berbagai PWF asumsi seperti terlihat pada tabel 16, dan perhitungan sesudah pengasaman matrik seperti terlihat pada tabel 17. 
Tabel 17 Laju Alir Sumur \#P Sesudah Pengasaman Dari Beberapa Harga Pwf Asumsi

\begin{tabular}{lllll}
\hline $\begin{array}{c}\text { Pwf } \\
\text { (Psi) }\end{array}$ & $\begin{array}{c}\text { Oil } \\
\text { (BOPD) }\end{array}$ & $\begin{array}{c}\text { Water } \\
\text { (BWPD) }\end{array}$ & $\begin{array}{c}\text { Fluida } \\
\text { (BFPD) }\end{array}$ & $\begin{array}{c}\text { Water Cut } \\
(\%)\end{array}$ \\
\hline 0 & 50.49 & 107.69 & 158.18 & 68.08089 \\
\hline 33 & 49.12 & 103.72 & 152.84 & 67.86358 \\
\hline 66 & 47.62 & 99.60 & 147.23 & 67.65262 \\
\hline 98 & 46.01 & 95.33 & 141.34 & 67.44755 \\
\hline 131 & 44.27 & 90.91 & 135.18 & 67.24786 \\
\hline 164 & 42.42 & 86.33 & 128.74 & 67.05307 \\
\hline 197 & 40.44 & 81.59 & 122.03 & 66.86262 \\
\hline 229 & 38.34 & 76.71 & 115.05 & 66.67592 \\
\hline 262 & 36.12 & 71.67 & 107.79 & 66.49226 \\
\hline 295 & 33.77 & 66.48 & 100.25 & 66.3108 \\
\hline 328 & 31.31 & 61.13 & 92.44 & 66.13046 \\
\hline 360 & 28.72 & 55.63 & 84.36 & 65.94977 \\
\hline 393 & 26.02 & 49.98 & 76.00 & 65.76669 \\
\hline 426 & 23.19 & 44.18 & 67.36 & 65.57806 \\
\hline 459 & 20.24 & 38.22 & 58.46 & 65.37877 \\
\hline 491 & 17.17 & 32.11 & 49.27 & 65.15972 \\
\hline 524 & 13.97 & 25.84 & 39.81 & 64.90268 \\
\hline 557 & 10.66 & 19.42 & 30.08 & 64.56477 \\
\hline 590 & 7.22 & 12.85 & 20.07 & 64.01449 \\
\hline 623 & 3.67 & 6.12 & 9.79 & 62.55412 \\
\hline 655 & 0.00 & 0.00 & 0.00 & 0.00 \\
\hline
\end{tabular}

\section{Perhitungan Berdasarkan Permeabilitas}

Berdasarkan data-data yang ada maka dilakukan perhitungan harga permeabilitas (K) pada reservoir dan dari perhitungan didapatkan harga permeabilitas sebelum pengasaman adalah sebesar $10,76 \mathrm{mD}$ dan setelah pengasaman sebesar $9,42 \mathrm{mD}$.

\section{KESIMPULAN}

Berdasarkan analisis yang dilakukan pada desain pengasaman matrik sumur \#H dan \#P Lapangan Falih dapat diperoleh beberapa kesimpulan, yaitu:

1. Untuk desain pengasaman matriks sumur \#H didapatkan peningkatan untuk masing-masing parameter yang dievaluasi sebelum dan sesudah dilakukan pengasaman yakni peningkatan produksi sebesar dari 80,24 BOPD, peningkatan Produktivity Indeks sebesar $0.8 \mathrm{bbl} / \mathrm{psi} / \mathrm{day}$, peningkatan produksi menggunakan metoda IPR Wiggins pada Pwf 77 Psia sebesar 47,98 Psia dan peningkatan permeabilitas sebesar $6.14 \mathrm{mD}$

2. Untuk desain pengasaman matriks untuk sumur \#P didapatkan kecenderungan penurunan paramater yang dievaluasi sebelum dan sesudah dilakukan pengasaman yakni terjadi penurunan produksi sebesar $5.95 \mathrm{BOPD}$, penurunan Produktivity indeks sebesar $0.01 \mathrm{bbl} / \mathrm{psi} / \mathrm{day}$, penurunan produksi berdasarkan metode IPR wiggins sebesar 6.87 $\mathrm{BOPD}$ dan penurunan 
permeabilitas sebesar $1.34 \mathrm{mD}$. Hal ini mengindikasikan pengasaman matriks tidak berhasil pada sumur \#P lapangan Falih.

\section{DAFTAR PUSTAKA}

Ayorinde, A., Granger, C., \& Thomas, R.L. (1992). The Application of Fluoboric Acid in Sandstone Matrix Acidizing: A Case Study. Paper presented at the $2 \mathrm{~s}^{\mathrm{st}}$ Annual Convention, Jakarta, Indonesia, October

Guin, J.A., \& Schechter, R.S. (1971). Matrix Acidization with Highly Reactive Acids. SPE Journal, v.251, 390-398.

Frenier, W.W. (2003). Review of Inorganic Scale Formation, Removal and Inhibition. Schlumberger.

Underwood. (2000). Analisa Kimia Kuantitatif (Ed. 4). New York.

Wiggins, M.L. (1994). Generalized Infowl Performance Relationships for Three Phase Flow. Paper presented at at the Production Operations Symposium held in Oklahoma City, OK, U.S.A., March 21-23.

Wiggins, M.L. (1991). Inflow Performance of Oil Wells Producing Water. PhD Disertation. Texas: A\&M University.

Williams, B.B., Gidley, J.L., \& Schechter, R.S. (1979). Acidizing Fundamentals (vol. 6). Monograph. SPE.

\section{LAMPIRAN}

Persamaan untuk menentukan Pr dan Pwf:

Pr $=($ Datum $-S F L) \times G F$

$\mathrm{GF}=\mathrm{SG}$ Campuran $\mathrm{x} 0.433$

SG campuran $:=((1-$ water cut $) \times$ SG oil $)+($ water cut $\times$ SG air $)$

Pwf Zona $=($ Datum - WFL $) \times G F$

Persamaan unutuk menentukan Pr rata-rata:

$\operatorname{Pr}=\frac{\operatorname{Pr} \text { Zona D }+ \text { Pr Zona A }}{2}$

Persamaan untuk menentukan Qw dan Qo sebelum test:

$\mathrm{Q}_{\text {water }}$ Sebelum $=\mathrm{Q}_{\text {test }} \times$ Water Cut

$\mathrm{Q}_{\text {oil }}$ Sebelum $\quad=\mathrm{Q}_{\text {test }}-\mathrm{Q}_{\text {water }}$

Persamaan untuk menentukan BHP rekah, Pmaks dan Imaks:

$B H P_{\text {rekah }}=G_{f} \times D$

$P_{\text {maks }}=\left(G_{f}-\right.$ gradien hidrostatik asam $) \times D$

$i_{\max }=\frac{4.917 \times 10^{-6} k h\left(G_{f} \times D-P_{r}\right)}{\mu \ln \left(\frac{r_{g}}{r_{w}}\right)}$

Persamaan untuk menentukan volume casing dan volume asam yang akan diinjeksikan:

Volume Casing $=$ Net Pay Zona D XCasing Volume Factor

$V_{\text {asam }}=\left(14 \frac{\text { gall }}{f t} \times\right.$ Interval Zona $\left.D\right)+$ Volume Casing 
Persamaan untuk menentukan volume over flush zona D:

Volume Casing Zona $A=$ Net Zona DXCasing Volume Factor

Volume Tubing = Depth Tubing Zona DX Tubing Volume Factor

Volume over flush $=$ Volume Casing Zona $A+$ Volume Tubing

Persamaan untuk menentukan Qo maks dan Qw maks:

$$
\begin{aligned}
& \frac{q_{o}}{q_{\text {o.max }}}=1-0.519167\left(\frac{P w f}{P r}\right)-0.481092\left(\frac{P w f}{P_{r}}\right)^{2} \\
& \frac{q_{w}}{q_{w, \max }}=1-0.7222235\left(\frac{P w f}{P r}\right)-0.284777\left(\frac{P w f}{P_{r}}\right)^{2}
\end{aligned}
$$

Persamaan untuk menentukan harga permeabilitas $(\mathrm{K})$

$$
K=\frac{Q_{o} \times \mu_{o} \times B_{0} \times \ln \left(\frac{r e}{r w}\right)}{0.00708 \times h \times(P r-P w f)}
$$

